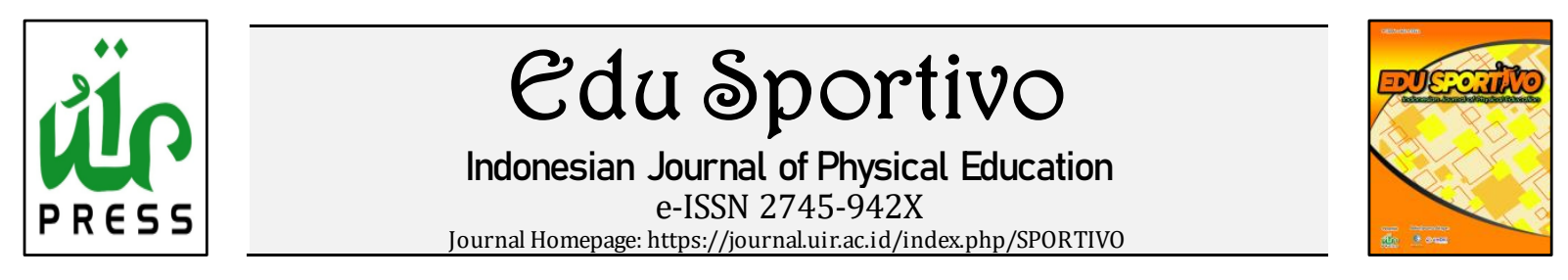

\title{
Analisis kemampuan forehand drive atlet tenis meja
}

\section{Analysis of the ability of forehand drives of table tennis athletes}

\author{
*1Dessi Novita Sari, ${ }^{2}$ Despita Antoni \\ *1,2Pendidikan Olahraga, Universitas Negeri Padang, Padang, Indonesia
}

Received: 06 July 2020; Accepted 07 August 2020; Published 14 August 2020

\begin{tabular}{|c|c|}
\hline ABSTRAK & ABSTRACT \\
\hline $\begin{array}{l}\text { Tujuan penelitian iniadalah untuk menganalisis kemampuan } \\
\text { forehand drive atlet tenis meja Semen Padang. Jenis } \\
\text { penelitian ini adalah deskriptif dimana peneliti hanya ingin } \\
\text { melihat keadaan sebenarnya di lapangan tentang } \\
\text { kemampuan forehand drive dalam bermain tenis meja. } \\
\text { Populasi dalam penelitianini adalah atlet tenis meja pemula } \\
\text { Semen Padang berjumlah } 18 \text { orang. Teknik pengambilan } \\
\text { sampel menggunakan proportional random sampling, } \\
\text { sehingga jumlah sampel berjumlah } 15 \text { orang. Untuk } \\
\text { mendapatkan data tentang kemapuan forehand drive } \\
\text { digunakan instrumen tes dengan sasaran di meja. Teknik } \\
\text { analisis yang digunakan sesuai denganjenis penelitian yaitu } \\
\text { dengan menggunakan penghitungan persentase. } \\
\text { Berdasarkan pengukuran dan analisa maka diperoleh hasil } \\
\text { penelitian yaitu atlet tenis meja Semen Padang memiliki } \\
\text { kemampuan forehand drive pada kategori sedang. }\end{array}$ & $\begin{array}{l}\text { The purpose of this study was to analyze the forehand drive } \\
\text { ability of the Semen Padang table tennis athletes. This type } \\
\text { of research is descriptive where the researcher only wants } \\
\text { to see the actual situation in the field about the ability of } \\
\text { forehand drive in playing table tennis. The population in this } \\
\text { study were } 18 \text { beginner table tennis athletes in Semen } \\
\text { Padang. The sampling technique used was proportional } \\
\text { random sampling, so the number of samples was } 15 \text { people. } \\
\text { To get data about the forehand drive capability, a test } \\
\text { instrument was used with a target on the table. The analysis } \\
\text { technique used is in accordance with the type of research, } \\
\text { namely by using the percentage calculation. Based on the } \\
\text { measurement and analysis, the results showed that the table } \\
\text { tennis athlete of Semen Padang has the ability forehand } \\
\text { drive in the medium category. }\end{array}$ \\
\hline Kata Kunci: Forehand; Drive; Tenis Meja & Keywords: Forehand; Drive; Table Tennis \\
\hline $\begin{array}{l}\text { *Corresponding Author } \\
\text { Email: dessi.novitasari.10@gmail.com }\end{array}$ & $\begin{array}{l}\text { Copyright ( } 12020 \\
\text { Edu Sportivo: Indonesian Journal of Physical Education }\end{array}$ \\
\hline
\end{tabular}

d.

https://doi.org/10.25299/es:ijope.2020.vol1(1).5253

How To Cite: Sari, D. N., \& Antoni, D. (2020). Analisis kemampuan forehand drive atlet tenis meja. Edu Sportivo: Indonesian Journal of Physical Education, 1(1), 60-65. https://doi.org/10.25299/es:ijope.202 0.vol1(1).5253.

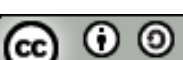

\section{PENDAHULUAN}

Seiring dengan perkembangan zaman, kegiatan yang menunjang kondisi fisik menjadi hal yang sangat diperlukan. Mengingat kebanyakan aktivitas di depan komputer, dan gadget yang membuat individu kurang kaya akan kegiatan motorik. Pada saat ini orang, klub atau tempat olahraga yang bisa memprogramkan kegiatan kondisi fisik, contohnya klub tenis meja Semen Padang. Dalam kegiatan tersebut dilakukan berbagai macam teknik, taktik, kondisi fisik dan mental. Hal ini menjadi tujuan dari penelitian, agar individu tetap bisa melakukan aktifitas fisik dengan teknik, taktik, kondisi fisik dan mental yang lebih baik lagi, sehingga kesehatan individu tetap terjaga.

Tenis meja dapat dimainkan dan dapat dinikmati oleh semua anggota keluarga, memberi gerak badan serta hiburan kepada pemain-pemain semua tingkat usia, baik usia dini, remaja, maupun dewasa (Mahendra, 2012). Tenis meja juga memberi banyak manfaat lain, yaitu dalam pertumbuhan fisik, mental, dan sosial yang baik. Melalui 
olahraga ini juga dapat mendidik siswa untuk rajin, tekun, ulet, disiplin, dan bertanggung jawab (Saripin, Agust \& Rafni, 2018). Tenis meja merupakan cabang olahraga yang mempunyai gerakan-gerakan yang unik dan dinamis dengan melibatkan seluruh anggota badan (Sari, 2012).

Tenis meja membutuhkan kelengkapan kondisi fisik agar mampu mendapatkan prestasi lebih tinggi, di samping penguasaan teknik, taktik serta strategi (Liskustyawati, 2017). Kondisi fisik di antaranya: kekuatan, kelincahan, kecepatan, daya tahan, kelentukan, dan koordinasi gerak. Selain kondisi fisik, aspek yang berperan penting dalam tenis meja yaitu grip, stance, stroke (pukulan), dan footwork. Permainan tenis meja bukan hanya masalah tangan saja, dari perkembangan teknik dapat dipahami untuk mencapai posisi yang maksimal harus ditunjang dengan sistem gerak langkah kaki yang makin sempurna, sehingga upaya untuk merebut kesempatan menyerang (Sari, 2017). Pada klub tenis meja Semen Padang, berbagai program latihanpun terus ditingkatkan. Adapun bentuk latihan mencakup teknik, taktik, kondisi fisik dan mental. Hal tersebut diberikan pelatih sesuai dengan atlet yang dilatihnya. Teknik dominan yang dipakai berikutnya ialah teknik chop, push, drive, dan yang paling sedikit ialah teknik block (Fajar, 2015).

Pelatih tenis meja memberikan beberapa bentuk latihan yang bisa menunjang dan mendukung agar keterampilan teknik dasar bagi atlet bisa menjadi lebih baik, salah satunya dengan variasi latihan. Banyak manfaat dari variasi latihan, yaitu: atlet lebih termotivasi dalam melaksanakan program latihan karena adanya variasi latihan yang lebih banyak; (2) atlet lebih termotivasi untuk mendapatkan variasi-variasi latihan baru; (3) atlet mendapatkan pengalaman variasi latihan yang lebih banyak sehingga memungkinkan membantu pada saat bertanding (Risma \& Jatra, 2020). Adapun variasi latihan pada tenis meja dimulai dari tingkat yang mudah atau pengenalan terhadap teknik dasar. David (2012) menjelaskan pada tahun 1903 dikeluarkan tentang petunjuk teknis terperinci mengenai karet bintik, pegangan penhold, dan taktik permainan.

Indra (2013) pemain yang baik dalam permainan tenis meja adalah pemain yang mengerti dan bisa melakukan teknik permainan tenis meja itu sendiri. Santi (2018) menjelaskan bahwa pemain yang memiliki kemampuan yang baik, namun tidak didukung oleh gerakan kaki yang baik, maka pemain tersebut masih kurang sempurna. Oleh karena itu, atlet perlu mendapat latihan dalam menguasai teknik-teknik latihan yang ada dari guru atau pelatihnya. Falahi (2019) menyatakan juga bahwa ada suatu yang perlu diketahui, yaitu metode latihan yang monoton. Jadi pada awal pertemuan siswa hanya disuruh pemanasan setelah itu stroke berpasangan dengan teman kemudian game.

Dalam bermain tenis meja terdapat beberapa teknik dasar keterampilan pukulan (stroke), antara lain: forehand, backhand, drive, push, chop, block, service, spin (Hasan, 2012). Syarifuddin dalam Tanuek (2011) menambahkan bahwa yang harus diperhatikan dalam teknik melakukan pukulan forehand adalah sikap permulaan dan gerakan. Sikap permulaan yaitu berdiri tegak, kedua kaki agak dibuka, kaki kiri agak ke depan, kedua lutut agak ditekuk, tangan yang memegang bed (tangan kanan) siku agak dibengkokan dalam keadaan siap untuk memukul bola yang datang, tangan kiri ditempatkan sedemikian rupa agar dapat membantu menjaga keseimbangan, pandangan ditujukan kepada lawan dan kepada bola yang akan datang. Gerakan yaitu ketepatan pengambilan posisi kaki, pinggul dan pinggang serta badan yang lainnya merupakan bagian yang penting dari kombinasi melakukan pukulan forehand yang tepat pada sasaran. Puji (2017) menyatakan pemain tenis meja tingkat pemula agar mampu menguasai teknik dasar dengan baik maka perlu menguasai pukulan forehand 
dan pukulan backhand.

Tujuan penelitian ini adalah untuk menganalisis kemampuan forehand drive atlet tenis meja Semen Padang. Agar dapat menjawab permasalahan penelitian pada kesalahan gerak yang terjadi pada saat atlet tenis meja melakukan teknik forehand drive, maka penting mengkaji dari sebuah gerakan yang terstruktur untuk perbaikan hasil dari forehand drive pada tenis meja. Hasil observasi tingkat kesalahan yang peneliti lihat bahwa teknik forehand drive yang lebih banyak mengalami kesalahan dalam pelaksanaannya, secara langsung diamati bahwa gerakan yang dilaksanakan secara hasil tidak memenuhi target tujuan. Dalam membenahi kesalahan melakukan forehand drive, pelatih harus mengevaluasi setiap tahapan teknik dasar forehand drive. Peneliti ingin menganalisis seberapa tingkat kesalahan teknik dasar forehand drive pada atlet tenis meja. Karena jika atlet tidak mempunyai teknik dasar forehand drive yang baik maka bola tidak dapat terarah ke meja lawan dengan tepat.

\section{METODE PENELITIAN}

Jenis penelitian ini adalah deskriptif dimana peneliti hanya ingin melihat keadaan sebenarnya di lapangan tentang kemampuan forehand drive atlet tenis meja Semen Padang. Menurut Nazir (2014) diperjelaskan bahwa metode penelitian deskriptif adalah metode dalam meneliti status dan mempelajari masalah-masalah dalam masyarakat serta tata cara yang berlaku dalam masyarakat dan situasi-situasi tertentu, termasuk tentang hubungan, kegiatan-kegiatan, sikap-sikap, pandangan-pandangan, serta prosesproses yang sedang berlangsung dan pengaruh-pengaruh dari suatu fenomena.

Populasi dalam penelitian ini adalah atlet tenis meja Semen Padang berjumlah 18 orang. Sugiyono (2013) mengemukakan sampel adalah bagian dari jumlah dan karakteristik yang dimiliki oleh populasi tersebut. Teknik pengambilan sampel menggunakan proportional random sampling, sehingga jumlah sampel berjumlah 15 orang. Untuk mendapatkan data tentang kemampuan forehand drive atlet tenis meja Semen Padang instrument tes yaitu tes ke sasaran meja, yang mana testee mengarahkan bola ke titik yang ditentukan, dan akan memperoleh angka sesuai tingkat kesulitan, (Sari, 2012). Teknik analisis yang digunakan sesuai dengan jenis penelitian yaitu dengan menggunakan analisis deskriptif persentase.

\section{HASIL PENELITIAN}

Berdasarkan hasil tes kemampuan forehand drive yang dilakukan, diperoleh skor maksimum $=26$ dan skor minimum $=18$. Di samping itu diperoleh nilai mean (ratarata) $=22$, median $=23$, modus $=23$, standar deviasi $=2,36$ dan range $=8$. Untuk lebih jelasnya distribusi frekuensi kelompok variabel kemampuan forehand drive dapat dilihat pada tabel 1 .

Tabel 1. Distribusi Frekuensi Kemampuan Forehand Drive

\begin{tabular}{cccc}
\hline Kategori & Kelas Interval & Fa & Fr (\%) \\
\hline Kurang sekali & $18-19$ & 3 & 20 \\
\hline Kurang & $20-21$ & 3 & 20 \\
\hline Sedang & $22-23$ & 7 & 46,67 \\
\hline Baik & $24-25$ & 0 & 0 \\
\hline Baik Sekali & $26-27$ & 2 & 13,33 \\
\hline & Jumlah & $\mathbf{1 5}$ & $\mathbf{1 0 0}$ \\
\hline
\end{tabular}

Pada tabel 1 di atas dari 15 orang sampel, sebanyak 3 orang (20\%) memiliki kemampuan forehand drive berkisar antara 18-19 dengan katergori kurang sekali, 
sebanyak 3 orang (20\%) memiliki kemampuan forehand drive berkisar antara 20-21 dengan kategori kurang, sebanyak 7 orang $(46,67 \%)$ memiliki kemampuan forehand drive berkisar antara 22-23 dengan kategori sedang, tidak seorangpun (0\%) memiliki kemampuan forehand drive, berkisar antara 24-25 dengan kategori baik, 2 orang (13,33\%) memiliki kemampuan forehand drive berkisar antara 26-27 dengan kategori baik sekali. Dari uraian di atas dapat dikemukakan dari 15 orang sampel, yang mempunyai skor di atas rata-rata ada 2 orang (13,33\%), yang mempunyai skor di dalam kelompok rata-rata ada 7 orang $(46,67 \%)$, dan yang mempunyai skor di bawah rata-rata ada 6 orang $(40 \%)$.

Berdasarkan penjelasan di atas disimpulkan bahwa kemampuan forehand drive yang dimiliki atlet tenis meja Semen Padang belum sesuai dengan harapan yang diinginkan, dengan ini dapat mempengaruhi atlet dalam pencapaian prestasi. Untuk lebih jelasnya dapat dilihat pada histogram distribusi frekuensi kemampuan forehand drive di bawah ini:

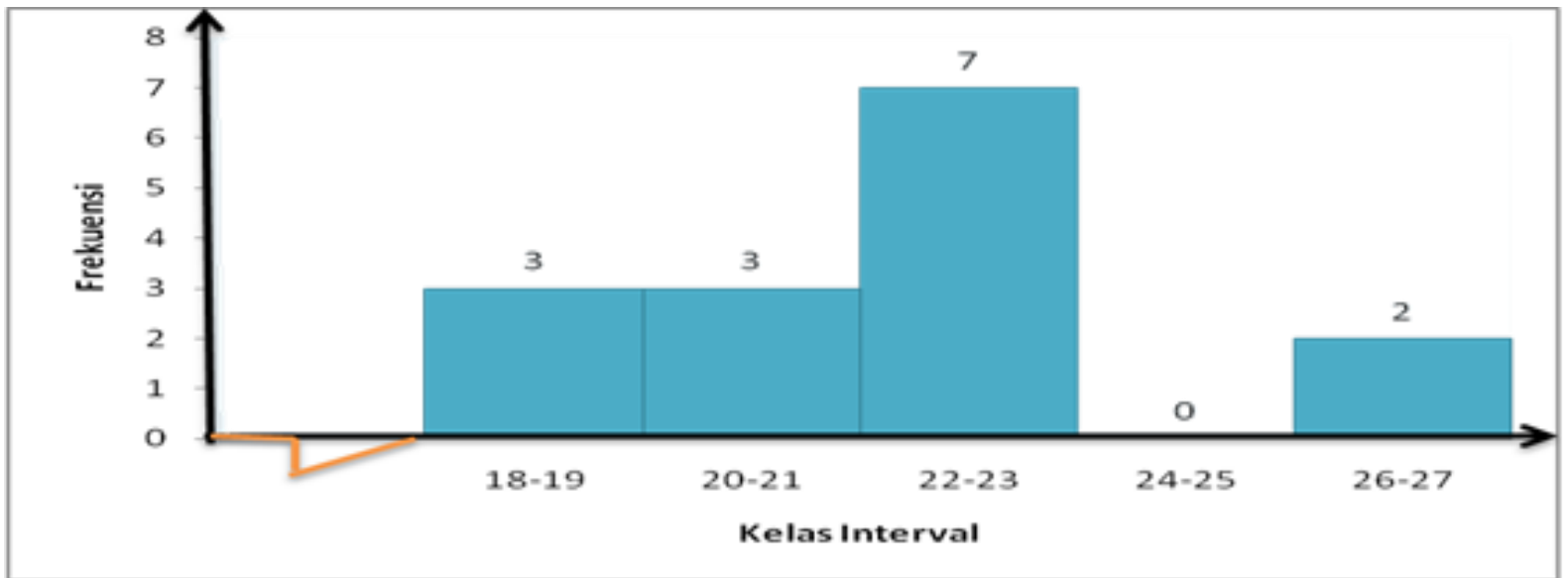

Gambar 1. Histogram Distribusi Kemampuan Forehand Drive

Berdasarkan hasil penelitian yang telah diuraikan di atas maka dapat diketahui bahwa atlet tenis meja Semen Padang memiliki kemampuan forehand drive pada kategori kurang sekali dengan persentase sebesar 20\%, pada kategori kurang dengan persentase sebesar 20\%, pada kategori sedang dengan persentase sebesar 46,67\%, pada kategori baik dengan persentase $0 \%$, pada kategori baik sekali dengan persentase $13,33 \%$.

\section{PEMBAHASAN}

Tujuan penelitian ini yaitu untuk menganalisis kemampuan forehand drive atlet tenis meja Semen Padang. Melihat hasil temuan dari penelitian ini, tentunya perlu mendapatkan perhatian yang serius dalam rangka mencapai prestasi. Dari kemampuan forehand drive dalam penelitian ini mempunyai nilai dan peran dalam memperoleh hasil terbaik dalam prestasi tenis meja. Bootsma (2013) menyatakan pada penelitian forehand drive yang dilakukan subjek ditunjukkan untuk meningkatkan jumlah bola yang mendarat pada target, dan pembelajaran juga terbukti dari peningkatan konsistensi arah yang ditargetkan. Novri (2017) menyatakan ada interaksi antara metode latihan dengan tingkat koordinasi mata tangan yang diterapkan ada keterampilan forehand drive tenis meja. Tenis meja membutuhkan kelengkapan kondisi fisik agar cepat dalam berlatih dan mampu mendapatkan prestasi lebih tinggi, di samping penguasaan teknik, taktik serta strategi dalam permainan (Yulianto, 2015). 
Hidayat (2015) menyatakan siswa yang belum dapat melakukan teknik pukulan forehand dan backhand dengan benar disebabkan penguasaan teknik, keterampilan dan kelincahan dalam bergerak. Selanjutnya Purwoko (2012) dalam penelitiannya untuk mengetahui hasil dari pukulan forehand siswa kelas V SD Negeri Krapyak Kecamatan Godean Kabupaten Sleman, diukur dalam bentuk back board test selama 30 detik. Hasil penelitian yang relevan didapatkan bahwa teknik forehand spin atau backhand spin merupakan teknik yang paling dibutuhkan pada tiap pertandingan yang sesunguhnya (Yulianto, 2015).

\section{KESIMPULAN}

Berdasarkan penjelasan sebelumnya maka dapat disimpulkan bahwa atlet tenis meja Semen Padang memiliki kemampuan forehand drive pada kategori sedang. Diharapkan kepada atlet tenis meja Semen Padang agar lebih giat dalam berlatih khususnya dalam meningkatkan kemampuan forehand drive tenis meja. Selanjutnya kepada peneliti selanjutnya untuk dapat melakukan penelitian dengan jumlah sampel yang banyak.

\section{DAFTAR PUSTAKA}

Bootsma, R. J. (2013) Acquiring an Attacking Forehand Drive: The Effects of Static and Dynamic Environmental Conditions. Journal Research Quarterly for Exercise and Sport, 62(3), 276-284. https://doi. org/10.1080/02701367.1991.10608724

David, A. (2012). Mengenal Tenis Meja. Jakarta: PT. Balai Pustaka (Persero).

Fajar, R. P. (2015). Study Analisis Keterampilan Teknik Bermain Cabang Olahraga Permainan. Jurnal Kesehatan Olahraga,3(1), 201-206.

Falahi, M. Q. (2019). Pengaruh Metode Latihan Mulltiball Terhadap Keterampilan Pukulan Drive Pada Ekstrakurikuler Tenis Meja. Jurnal Pendidikan Olahraga Dan Kesehatan, 7(3), 291-295.

Hasan, A. N. (2012). Artikel Tenis Meja. https://salamadian.com/pengertian-tenis-meja.

Hidayat, T. (2015). Kemampuan Pukulan Forehand Dan Backhand Dalam Permainan Tenis Meja Siswa Kelas V Sekolah Dasar Negeri Krapyak Kecamatan Godean Kabupaten Sleman. Fakultas Ilmu Keolahragaan.

Indra. (2013). Meningkatkan Kemampuan Pukulan Backhand Dalam Permainan Tenis Meja Dengan Menggunakan Metode Latihan Memantulkan Bola Kedinding Pada Siswa Putra Kelas VIII SMP Negeri Muaro Jambi.

Liskustyawati, H. (2017). Tes Fisik Tenis Meja Untuk Kelompok Umur 13 - 15 Tahun. Jurnal Penjakora,3(2), 10-18. https://doi.org/10.1017/CB09781107415324.004

Mahendra, A. (2012). Kelentukan Pergelangan Tangan dan Koordinasi Mata Tangan Dalam Pukulan Forehand Tenis Meja. Journal of Sport Sciences and Fitness, 1(1), 1116. 
Nazir, M. (2014). Metode Penelitian. Bogor: PT. Ghalia Indonesia.

Novri, A. (2017). Pengaruh Metode Latihan Multiball dan Koordinasi Mata Tangan terhadap Peningkatan Keterampilan Forehand Drive Tenis Meja. Journal of Physical Education and Sports, 6(2), 179-185.

Puji, L. (2017). Kontribusi Kemampuan Backhand dan Forehand Drive ke Dinding Terhadap Kemampuan Bermain Tenis Meja Mahasiswa PJKR FKIP Universitas Bengkulu. KINESTETIK : Jurnal Ilmiah Pendidikan Jasmani, 1(1), 40-43.

Purwoko, H. (2012). Tingkat Keterampilan Pukulan Forehand Drive Dalam Permainan Tenis Meja Peserta Ekstrakurikuler SD Negeri Guwosari Pajangan Kabupaten Bantul Tahun 2012. Universitas Negeri Yogyakarta.

Risma, N., \& Jatra, R. (2020). Pengaruh latihan variasi terhadap kemampuan servis atas bolavoli pada mahasiswi putri unit kegiatan mahasiswa penjaskesrek. Journal of Sport Education (JOPE), 2(2), 55-60.

Santi, A. (2018). Pengaruh Metode Latihan Multiball dan Latihan Dengan Pemain Lain Terhadap Ketepatan Forehand Drive Pada Siswa Ekstrakulikuler Tenis Meja SMA Negeri 1 Jalan Cagak Tahun 2018. BIORMATIKA Jurnal Ilmiah FKIP Universitas Subang, 4(2), 25-37.

Sari, D. N. (2012). Hubungan Kekuatan Otot Lengan dan Kelentukan Togok Terhadap Keterampilan Forehand Drive Atlet Tenis Meja Semen Padang. Universitas Negeri Padang.

Sari, D. N. (2017). Analisis Kemampuan Footwork Tenis Meja Mahasiswa UKO Tenis Meja Universitas Negeri Padang. Sport Science: Jurnal Sain Olahraga Dan Pendidikan Jasmani, 17(2), 101-107.

Saripin, S., Agust, K., \& Rafni, R.(2018). Hubungan Antara Fleksibilitas dengan Pergelangan Tangan Bagian Belakang Terhadap Pembelajaran Tenis Meja Dalam Program Pendidikan Jasmani Kesehatan Mahasiswa dan Rekreasi. Journal of Sport Education (JOPE), 1(1), 17-21.

Sugiyono. (2013). Metode Penelitian Pendidikan. Bandung: Alfabeta.

Tanuek, A. (2011). Hubungan Kelentukan Pergelangan Tangan dengan Ketepatan Melakukan Pukulan Forehand dalam Permainan Tenis Meja.

Yulianto, F. R. P. (2015). Study Analisis Ketermpilan Teknik Bermain Cabang Olahraga Permainan Tenis Meja. Jurnal Kesehatan Olahraga, 3(1), 201-206. https://doi.org/10.1017/CB09781107415324.004 